\title{
Estimating the Number of Trees in Margasari Mangrove Forests of Lampung Through Aerial Images Using Adaptive Thresholding and Contour Extraction Methods
}

\author{
Mona A Batubara ${ }^{1}$ Syaiful Alam ${ }^{1}$ Khoirin Nisa $^{2}$ Rizka WA Utami ${ }^{1}$ \\ Helmy Fitriawan ${ }^{1}$ Ardian Ulvan ${ }^{1, *}$ \\ ${ }^{I}$ Department of Electrical Engineering, Universitas Lampung, Bandar Lampung, Indonesia \\ ${ }^{2}$ Department of Mathematics, Universitas Lampung, Bandar Lampung, Indonesia \\ "Corresponding author.Email: ardian.ulvan@eng.unila.ac.id
}

\begin{abstract}
Estimating number of trees with field plots located in remote or inaccessible areas can be a costly and timely endeavor. Unmanned aerial vehicle (UAV) remote sensing allowing for the estimation of the forest vegetation offers an alternative to traditional ground-based forest measurements. It is an important supplement to traditional aerial and satellite remote sensing due to its flexible, fast and cost-effective capability for acquiring very high spatial resolution imagery. In this study, we explored the application of UAV to monitoring mangrove forests in Margasari Lampung Indonesia. Using the UAV, we collected aerial photos of the Margasari mangrove area. The adaptive thresholding and contour extraction methods were applied to measure the number of trees of the mangrove forest.
\end{abstract}

Keywords: Remote Sensing, Image processing, Forest Monitoring, UAV.

\section{INTRODUCTION}

Indonesia is an archipelago consisting of more than 17,508 islands and has a coastline length of up to $81,000 \mathrm{~km}$ [1]. Most of the coastline is surrounded by mangrove forests. Indonesia is a region that has the largest mangrove ecosystem in the world. Mangroves have many important roles for human life including carbon sequestration, remediation of pollutants, guarding the coast from abrasion and storm waves, and shelter for various types of fauna [2-3].

Mangrove forests need to be managed as much as possible to improve the quality and quantity of mangrove forests that can affect the economic life of coastal communities and the balance of ecosystems. One of the criteria for success in handling mangrove forests is the increase in the number of mangrove trees in a certain period. To obtain information on the quantity or number of mangrove trees, it can be obtained by processing digital images through remote sensing data using Unmanned Aerial Vehicle (UAV) fixed wing types.

The process of taking aerial imagery using UAV has several advantages including being able to take pictures from a predetermined height and simplify taking aerial imagery since the vehicle can fly automatically. Furthermore, the identification of the number of mangrove trees can be conducted automatically through digital image processing with an integrated camera within the Unmanned Aerial Vehicle (UAV).

Image processing is a transformation process from an image to another image that has better information and quality. Basically, image processing is used to manipulate and modify an image using a specific algorithm [4-7].

Unmanned Aerial Vehicle (UAV) or also called an unmanned aerial vehicle is an aircraft that can fly without a pilot inside the vehicle and uses aerodynamic properties as lift. Unmanned aerial vehicles can air automatically using a standalone navigation system and are capable of carrying loads or payloads [8-9]. The air rides in the form of the skywalker type as shown in Figure 1. 


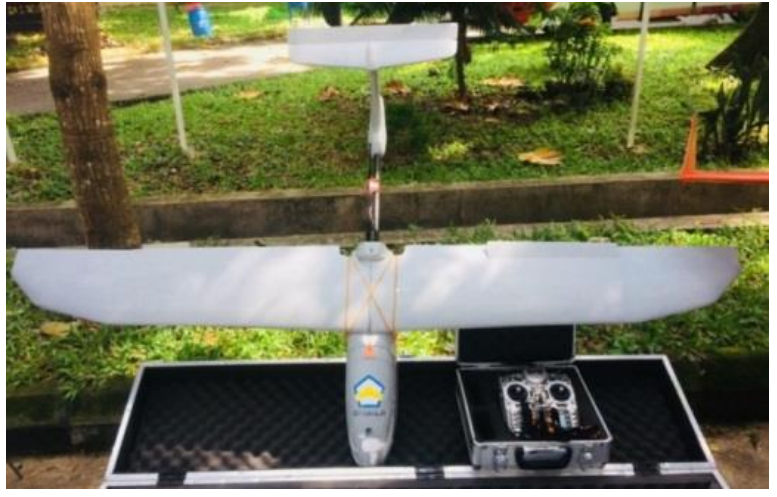

Figure 1 Skywalker unmanned aerial vehicle

The use of UAVs is very effective because it has a low level of risk, especially if necessary, observations in areas that are difficult to reach. UAVs can also be used for remote sensing so that the monitoring process is faster, has high efficiency, and has high resolution [10].

Studies on the use of UAV for ecosystem monitoring have been done in the recent years, one can see e.g. [11-14]. In this paper we explored the application of UAV to monitoring mangrove forests in Margasari Lampung Indonesia.

\section{DATA AND METHODS}

\subsection{Collection of Image Data}

The process of taking images data through aerial photography is done using a Sony Nex-5 camera that is integrated with a fixed wing UAV vehicle. This study uses data in the form of orthophoto maps and processed using image processing with the python programming language and OpenCV Library. The image is in the form of an RGB (red-green-blue) image that has dimensions of $38,440 \times 32,380$ pixels with an image format that is TIFF.

\subsection{Methods}

For orthophoto maps of mangrove forests of this research follows the flowchart as shown in Figure 2.

\section{RESULTS AND DISCUSSION}

\subsection{Image Input}

The image is inputted by using the command "cv2.imread". The processed image has a large matrix dimension that is $38,440 \times 32,380$ pixels so it is necessary to do the image sharing process to simplify the image processing process. In this study the image is divided into 4 parts as shown in Figure 3.

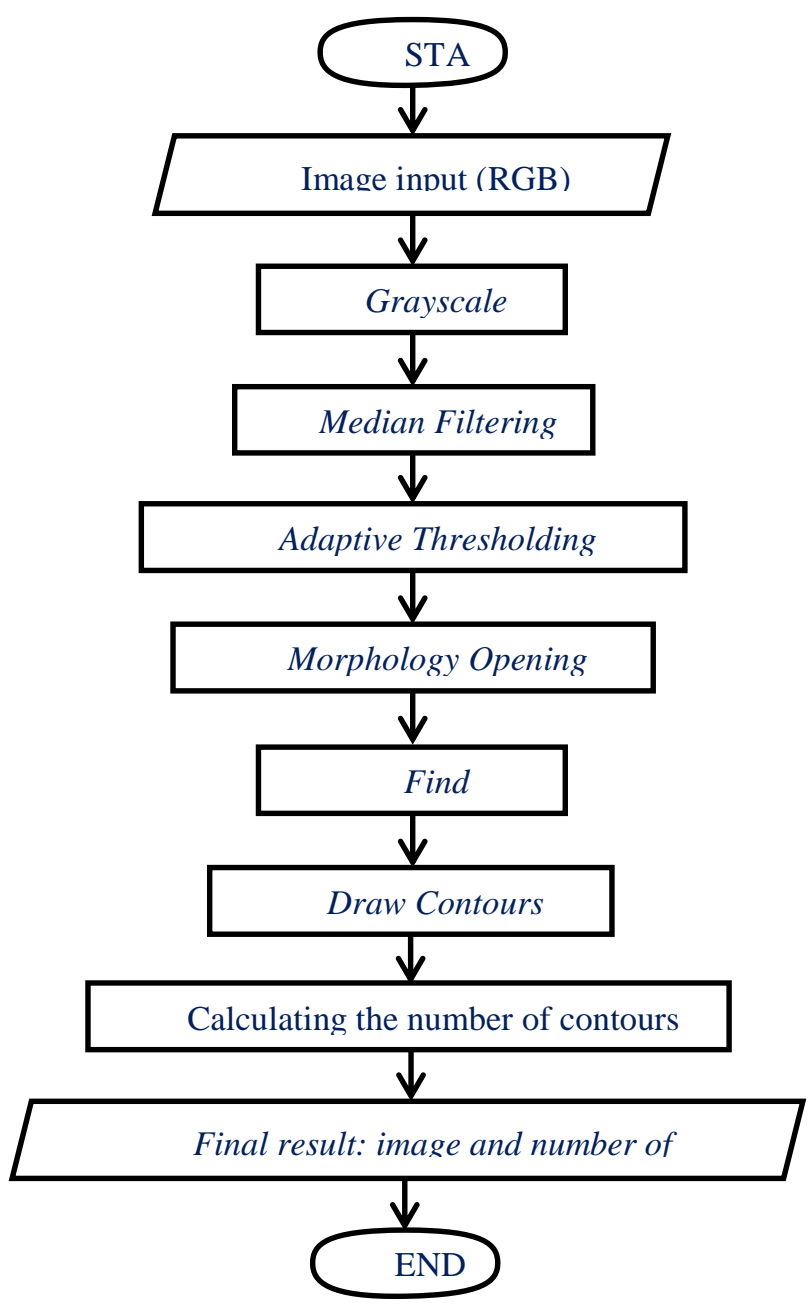

Figure 2 Research flowchart

\subsection{Image Conversion}

RGB images that have gone through the process of dividing the image, will then be converted to gray or grayscale images with the command "cv2.COLOR_GBR2GRAY" as shown in Figure 4. RGB images must be converted into gray images to be able to be processed using adaptive thresholding method. Another advantage of the gray image is that it reduces the computational burden during the process so that the time needed in the image processing process will be more effective [15]. 


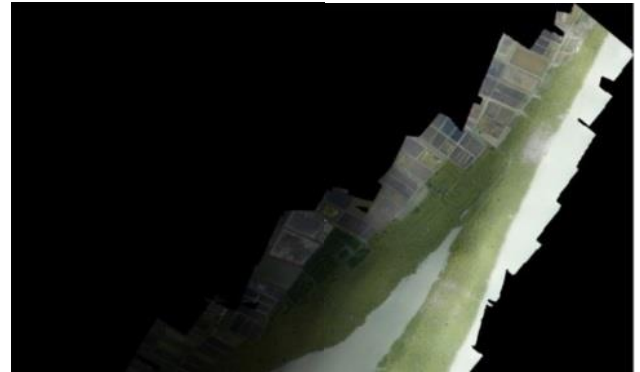

(a)

(b)

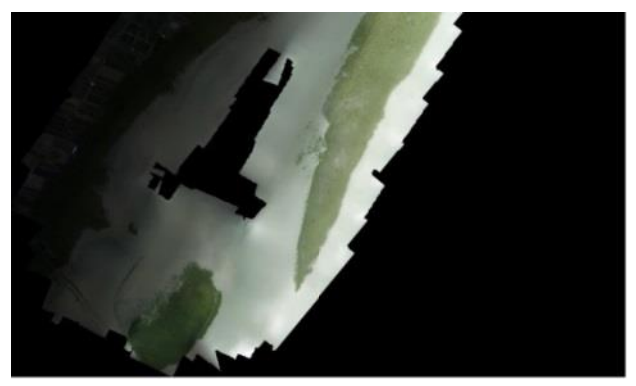

(c)

(d)

Figure 3 Results of dividing the aerial image into four parts

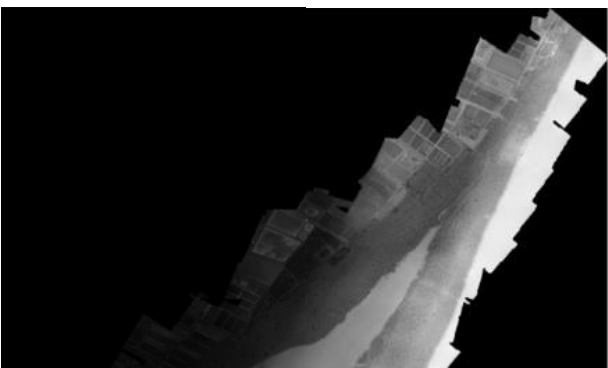

(a)

(b)

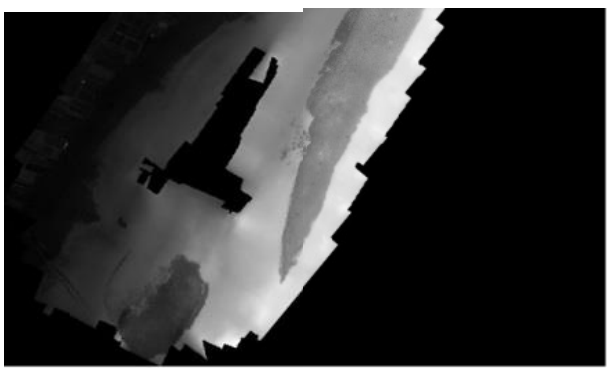

(b)

(d)

\subsection{Median Filtering}

To eliminate noise, the median filtering process is carried out with the command "cv2.medianBlur". The purpose of the median filtering process is to eliminate noise, so that in the next process the noise will not be detected as an object.

\subsection{Adaptive Thresholding}

Adaptive thresholding method uses the command "cv2.adaptiveThreshold" and produces a binary image. The advantages of the adaptive thresholding process are being able to handle all parts of the image even though there are images with different levels of illumination so that the results of the binary process are better. The image form after an adaptive thresholding operation is shown in Figure 5.

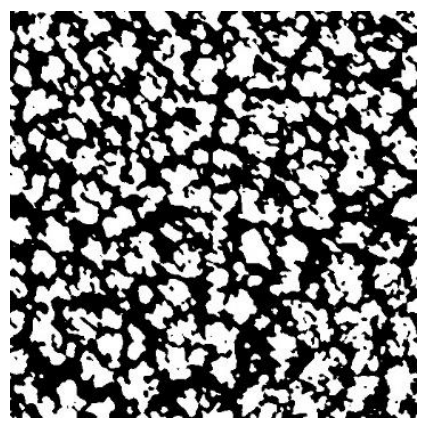

Figure 5 The result of adaptive thresholding

\subsection{Opening Morphology Operation}

The type of morphological operation used in this study, namely the opening operation, the goal is to eliminate noise in the image. The opening morphology process uses the command "cv2.MORPH_OPEN". The opening operation in this study is used to separate objects that stick together so that the object of the mangrove tree is more easily recognized.

\subsection{Contour Extraction}

The next operation is to find contours and draw contours. Contours find is used to search for an object so that it can be analyzed further. Operation find contours uses the command "cv2.findContours". Draw contours use the command "cv2.drawContours" which functions as a process of segmenting objects by giving lines that surround each object that have been successfully segmented with predetermined limits. The image results from the find process contours and draw contours are shown in Figure 6. 


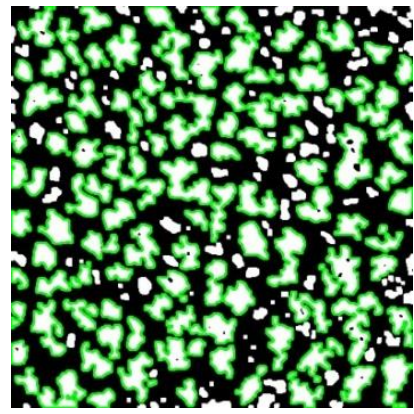

Figure 6 The result of contour extraction

After the object of the mangrove tree is known, the next process is to count the number of white objects that have a green edge so that information about the number of mangrove trees will be known.

\subsection{Mangrove Tree Calculation Results}

In this study, a manual visual calculation of 32 sample images and calculations was carried out directly in Margasari Mangrove Forest, East Lampung. The results of these calculations are compared with the results of automatic calculations using a program to obtain an error tolerance value. In the adaptive thresholding process an experiment was conducted with five constants, namely $2,1,0,-1$, and -2 . A constant that produces the lowest error that will be used to calculate the total number of trees.

The image samples used were 32 images. Each of these images has a dimension of $500 \times 500$ pixels in the .TIF image format. The manual calculation process is performed on samples that have been printed out and then calculated through visual vision. Changes in constants in the adaptive thresholding process affect the number of trees calculated so that the percentage of errors produced also varies. The comparison of the results of calculations on 32 image samples and automatic calculations using the program can be illustrated as the graph shown in Figure 7.

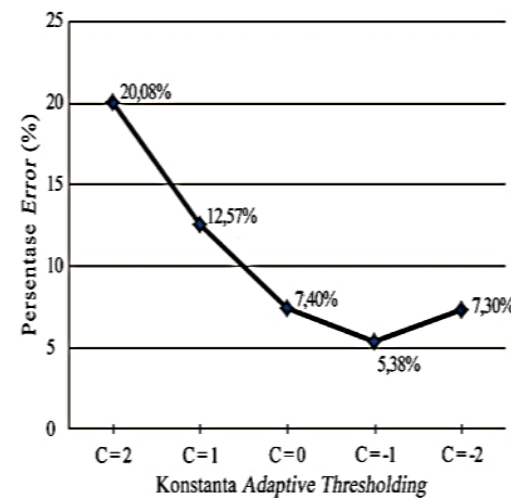

Figure 7 Error value in image samples with different $\mathrm{C}$ values
In this study also carried out a comparison between the results of calculations directly in Margasari Mangrove Forest. The calculation process is done by putting 4 stakes (orange banners) on a predetermined location to then be counted directly in the mangrove forest. The direct calculation process is only carried out in four different locations because most of the mangrove forest area is difficult to reach. The direct comparison of the results of calculations and automatic calculations using the program can be illustrated as the graph shown in Figure 7.

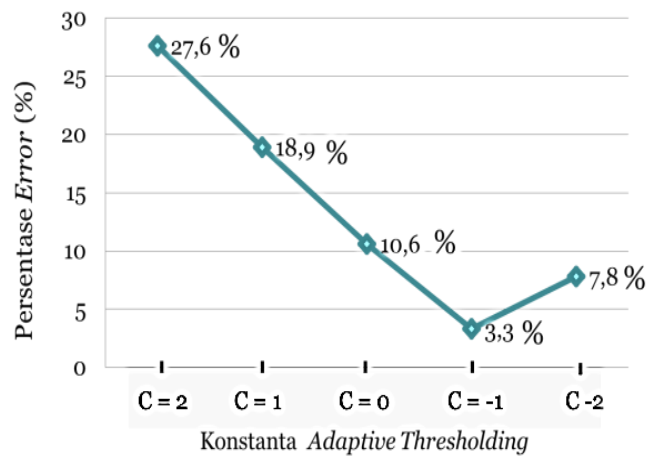

Figure 8 Percentage error value in the comparison between direct calculation and automatic calculation

The results of image processing using adaptive thresholding and contour extraction methods also have fairly good accuracy, because the objects detected by the program match the original magrove tree objects as shown in Figure 9.

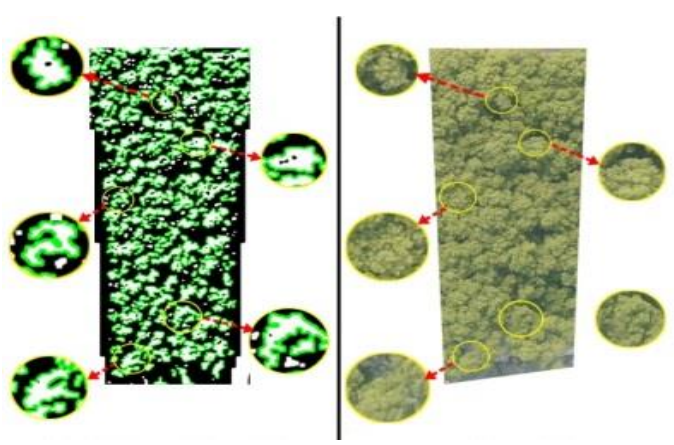

Fig. 9. Comparison of results of image processing (left) with original image (right)

Based on the results of a comparison between the calculation of mangrove trees directly in Margasari Mangrove Forest, Labuhan Maringgai District, East Lampung Regency with automatic calculation using the program resulted in a percentage error or error tolerance of $3.3 \%$. This value is used as a tolerance for errors in the calculation of the overall mangrove tree on the orthophoto map of Margasari Mangrove Forest, East Lampung. The results of calculations on the orthophoto map of mangrove forests that have been 
divided into four parts, produce the number of trees as shown in Table 1.

Table 1. Results of tree calculations on orthophoto maps of mangrove forests

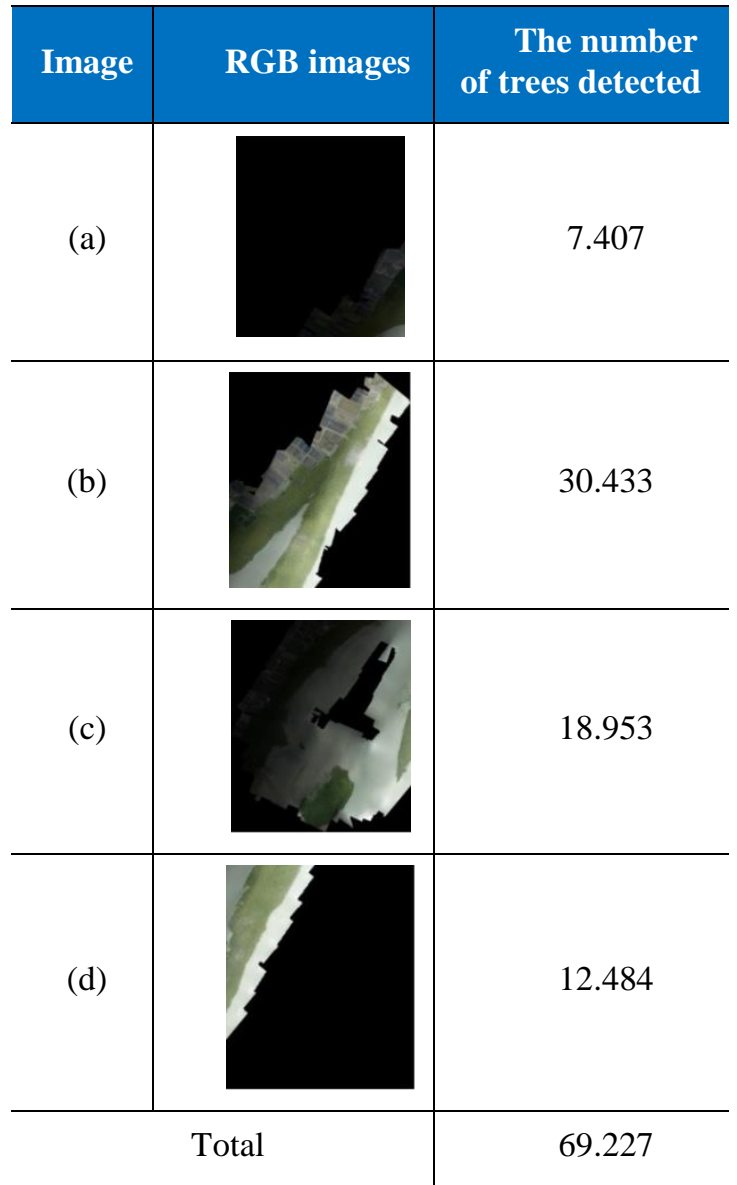

The automatic calculation process for each image spends the same time, which is 54 seconds. There is a difference that is not too far away for the calculation process in images that have dimensions of $500 \times 500$ pixels (21 seconds) with images measuring 16,190 x 19,220 pixels, this is because when the program reads the image it takes 21 seconds. So the number of mangrove trees in Lampung Mangrove Center (LMC) Margasari, Kec. Labuhan Maringgai, East Lampung based on automatic calculations using image processing is as many as 69,277 trees with an error tolerance of $3.3 \%$.

\section{CONCLUSIONS}

Based on the results of the research that has been made the following conclusions are obtained.

1. The number of mangrove trees in Margasari Mangrove Forest succeeded as many as 69,227 trees using adaptive thresholding and contour extraction methods with an error tolerance of $3.3 \%$.
2. The adaptive thresholding constant can affect the process of separation between objects in the form of mangrove trees and the background, namely water, soil, swamps, and ponds.

3. Based on the results of testing using different adaptive thresholding constants, the constant value that produces the lowest error value is when the constant is -1 , the results of manual calculations on 32 image sample data produce an error of $5.38 \%$ and in the calculation results directly in Margasari Mangrove Forest produces an error of 3.3\%.

4. The process of calculating the number of trees only takes 21 seconds for images measuring $500 \times 500$ pixels and 54 seconds for images measuring $16,190 \times 19,220$ pixels.

\section{REFERENCES}

[1] Onrizal and Kusmana, C. (2008). Studi Ekologi Hutan Mangrove di Pantai Timur Sumatera Utara. Biodiversitas, 9 (1), 25- 29.

[2] Nagelkerken, I., Blaber, S., Bouillon, S., Green, P., Haywood, M., Kirton, L.G., Meynecke, J-O, Pawlik, J. Penrose, H. Sasekumar, A., and Somerfield, P. (2008). The habitat function of mangroves for terrestrial and marine fauna: A review. Aquatic Botany,89. 10.1016.

[3] Hutchison, J., Spalding, M. and zu Ermgassen, P. (2014). The Role of Mangroves in Fisheries Enhancement. The Nature Conservancy and Wetlands International.

[4] Young, I.T., Gerbrands, J.J. and van Vliet, L. J. (2007). Fundamentalsof Image Processing Version 2.3. Delft University of Technology.

[5] Reshi, I. A. (2017). New Techniques Used for Image Enhancement. IOSR Journal of VLSI and Signal Processing (IOSR-JVSP), 7 (6),18-22.

[6] Hole1, K.R., Gulhane, .S., Shellokar, N.D. (2013). Application of Genetic Algorithm for Image Enhancement and Segmentation.International Journal of Advanced Research in Computer Engineering \& Technology (IJARCET), 2 (4), 1342-1346.

[7] Maini, R. and Aggarwal, H.. (2010). A Comprehensive Review of Image Enhancement Techniques. Journal of Computing, 2 (3), 8-13.

[8] Franceschini, F., Mastrogiacomo, L. and Pralio, B. (2010). An Unmanned Aerial Vehicle-based System for Large Scale Metrology Applications. International Journal of Production Research, 48 (13), 3867-3888. 
[9] Khan, S. A., Aabid, A. and Ali Baig, M. A. (2018). Design and Fabricaion of Unmanned Aerial Vehicle for Multi-Mission Tasks. International Journal of Mechanical and Production Engineering Research and Development (IJMPERD), 8 (4), 475-484.

[10] Gao, Z., Song, Y., Li, C., Zeng, F. and Wang, F. (2017). Research On The Application Of Rapid Surveying And Mapping For Large Scare Topographic Map By UAV Aerial Photography System. The International Archives of the Photogrammetry, Remote Sensing and Spatial Information Sciences, XLII (2), 121-125.

[11] Kuenzer, C., Bluemel, A., Gebhardt, S. Vo Quoc, T. and Dech, S. (2011). Remote Sensing of Mangrove Ecosystems: A Review. Remote Sens, 3, 878-928; doi:10.3390/rs3050878.

[12] Ballaria, D., Orellanab, D., Acostaa. E., Espinozac, A. and Morochoc, V. (2016). UAV Monitoring for
Enviromental Management in Galapagos Islands. The International Archives of the Photogrammetry, Remote Sensing and Spatial Information Sciences, XLI (B1,

[13] Cao, J., Leng, W., Liu, K., Liu, L., He, Z. and Zhu, Y. (2018). Object-Based Mangrove Species Classification Using Unmanned Aerial Vehicle Hyperspectral Images and Digital Surface Models. Remote Sens, 10, 89; doi:10.3390/rs10010089.

[14]Fatoyinbo, L. (2014). Remote sensing and the management of rare ecosystems: mangroves as a study case. NASA Goddard Space Flight Center Remote Sensing for Conservation May 20-22, 2014, Zoological Society of London.

[15] Mordvintsev, A.and Abid Rahman, K. (2017). OpenCV-Python Tutorials Documentation Release 1. GSoC. 